\title{
MODELLING OF DATA WAREHOUSE ON FOOD DISTRIBUTION CENTER AND RESERVES IN THE MINISTRY OF AGRICULTURE
}

\author{
Edi Purnomo Putra'; ${ }^{1}$ Fifilia $^{2}$; Lay Christian ${ }^{3}$; Hantze Sudarma ${ }^{4}$ \\ 1,2,3,4 School of Computer Science, BINUS University \\ Jln. K.H. Syahdan No. 9 Palmerah, Jakarta 11480 \\ 1eputra@binus.edu; ${ }^{2}$ fifilia@binus.edu; ${ }^{3}$ Ichristian@binus.edu; ${ }^{4}$ hantze@binus.edu
}

\begin{abstract}
The purpose of this study is to perform database's planning that supports Prototype Modeling Data Warehouse in the Ministry of Agriculture, especially in the Distribution Center and Reserves in the field of distribution, reserve and price. With the prototype of Data Warehouse, the process of data analysis and decision-making process by the top management will be easier and more accurate. Research's method used was data collection and design method. Data warehouse's design method was done by using Kimball's nine steps methodology. Database design was done by using the ERD (Entity Relationship Diagram) and activity diagram. The data used for the analysis was obtained from an interview with the head of Distribution, Reserve and Food Price. The results obtained through the analysis incorporated into the Data Warehouse Prototype have been designed to support decision-making. To conclude, Prototype Data Warehouse facilitates the analysis of data, the searching of history data and decision-making by the top management.
\end{abstract}

Keywords: data warehouse, database, distribution, modeling.

\begin{abstract}
ABSTRAK
Tujuan Penelitian ini adalah untuk melakukan perancangan Database yang mendukung Prototype Permodelan Data Warehouse di Kementerian Pertanian RI khususnya di Pusat Distribusi dan Cadangan pada bidang distribusi, bidang cadangan dan bidang harga. Dengan adanya prototype Data Warehouse, proses analisis data dan proses pengambilan keputusan oleh top management akan lebih mudah dan akurat. Metode penelitian yang digunakan adalah metode pengumpulan data dan metode perancangan. Metode perancangan Data Warehouse dilakukan dengan menggunakan Sembilan langkah metodologi dari Kimball. Perancangan Database dilakukan dengan menggunakan ERD (Entity Relationship Diagram) dan activity diagram. Data yang digunakan untuk analisis diperoleh dari melakukan wawancara dengan kepala bidang Distribusi, bidang Cadangan dan bidang Harga Pangan. Hasil yang diperoleh melalui analisis tersebut dimasukkan ke dalam Permodelan Data Warehouse yang telah dirancang untuk mendukung pengambilan keputusan. Kesimpulan yang didapat adalah Prototype Data Warehouse memudahkan analisis data, memudahkan pencarian data history serta memudahkan pengambilan keputusan oleh top management.
\end{abstract}

Kata kunci: data warehouse, basis data, pendistribusian, permodelan. 


\section{PENDAHULUAN}

Dewasa ini pangan merupakan salah satu masalah terbesar yang semakin sulit untuk ditangani dikarenakan jumlah manusia yang semakin banyak dari tahun ke tahun sehingga menyebabkan konsumsi pangan menjadi meningkat dan secara otomatis tuntutan akan kebutuhan panganpun semakin meningkat. Hal ini menjadi tantangan bagaimana cara mengumpulkan informasi yang berkaitan dengan seluruh aktivitas distribusi maupun aliran cadangan pangan pada setiap lumbung serta informasi harga di setiap daerah yang di peroleh dari petugas di setiap daerah, mampu menghasilkan informasi yang dapat digunakan untuk membuat keputusan atau kebijakan baru guna membantu mewujudkan visi dan misi Pusat Distribusi dan Cadangan.

Tantangan tersebut mengharuskan adanya suatu metode atau cara yang tepat untuk dapat mengambil sebuah kebijakan baru maupun pengambilan keputusan. Metode pengambilan keputusan yang dimaksudkan tersebut dapat berjalan dengan baik dan tepat, jika di dukung sebuah komponen yang mampu merangkum data aliran distribusi, cadangan maupun pengumpulan harga yang sangat besar ukurannya. Data warehouse berfungsi sebagai media penyimpanan historical data yang sudah terintegrasi, biasanya berasal dari beberapa sumber data yang digunakan sebagai pendukung untuk membantu top management dalam mengambil sebuah keputusan yang tepat pada suatu instansi dengan bantuan antar muka berbentuk pivot table dan atau sebuah report yang fleksibel dimana dapat melihat laporan dari berbagai sudut pandang serta dapat melakukan drill down.

Pada akhir perancangan prototype data warehouse ini, diharapkan dapat mengurangi resiko kegagalan dalam implementasi data warehouse serta hasil analisis proses ketiga bidang distribusi, cadangan dan harga pangan yang berjalan dapat memberikan usulan yang membangun ataupun solusi yang lebih baik guna membantu pengambilan keputusan yang cepat, tepat, dan fleksibel dalam lingkup bidang Distribusi, bidang Cadangan dan bidang Harga Pangan.

Menurut Connolly dan Begg (2005), database adalah sekumpulan koleksi dari data yang terhubung secara logikal, dan deskripsi dari data-data tersebut, yang dirancang untuk memenuhi kebutuhan informasi dari suatu perusahaan. Menurut Turban, Rainer, dan Begg (2005), OLTP (Online Transaction Processing) adalah Transaction Processing System (TPS) beroperasi pada arsitektur client/server, memperbolehkan pemasok organisasi untuk masuk TPS melalui ekstranet dan memperhatikan tingkat persediaan perusahaan atau jadwal produksi.

Menurut Connolly dan Begg (2005), OLAP (Online Analytical Processing) adalah perpaduan dinamis, analisis, dan konsolidasi dari data multi-dimensional berukuran besar. Data Mart menurut McLeod dan Schell (2007), adalah database yang berisi data yang hanya menjelaskan segmen dari operasi perusahaan. Menurut Inmon (2002), data warehouse adalah koleksi data yang berorientasi subjek (subject oriented), terintegrasi (integrated), memiliki rentang waktu (time variant), dan tidak mengalami perubahan (nonvolatile) untuk mendukung proses pembuatan keputusan manajemen.

Menurut Inmon (2002), data mengalir ke dalam data warehouse dari lingkungan operasional. Biasanya data mengalami transformasi signifikan dari tingkat operasional ke tingkat data warehouse. Data dilewatkan dari current detail data ke older detail. Setelah data diringkas, data tersebut dilewatkan dari current detail ke lightly summarized data, kemudian dari lightly summarized data ke highly summarized data 


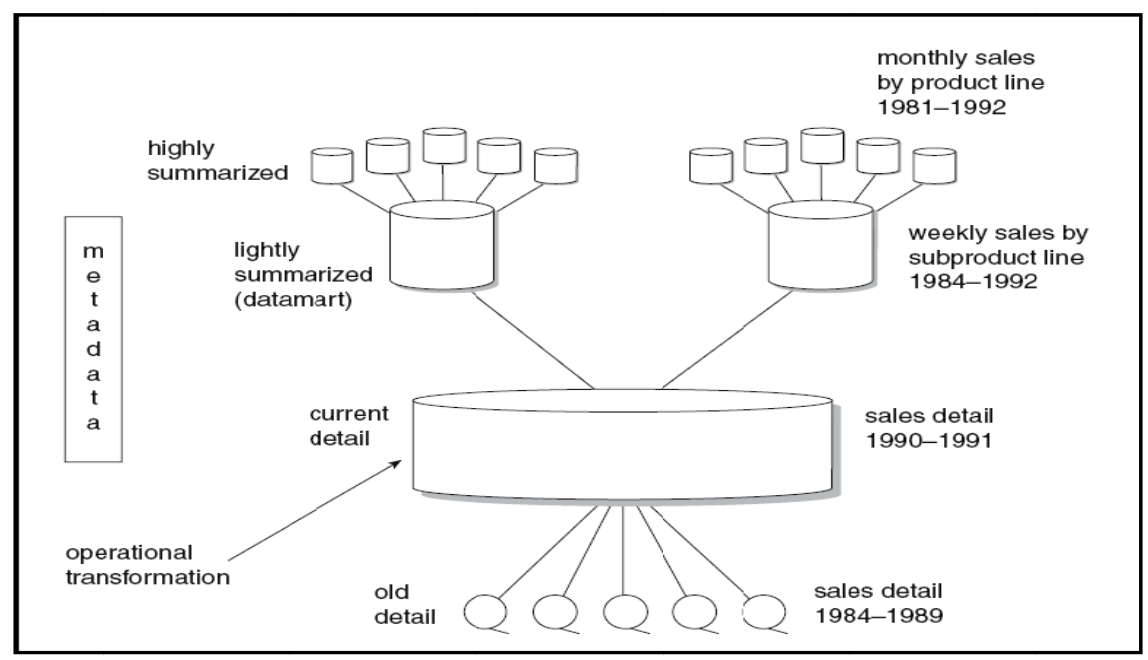

Gambar 1 Struktur Data Warehouse

Menurut Inmon (2002), metadata adalah data mengenai data atau deskripsi dari struktur, isi, kunci, indeks, dan lain-lain dari data. Menurut Connolly dan Begg (2005), Arsitektur Data Warehouse terdiri dari struktur atau komponen-komponen yang saling menunjang satu sama lain dalam membangun sebuah data warehouse. Menurut Ponniah (2001), skema bintang (star schema) adalah teknik dasar desain data untuk data warehouse. Struktur skema bintang adalah suatu struktur yang dapat dengan mudah dipahami dan digunakan oleh pengguna.

Berdasarkan Ralph Kimball seperti yang dikutip oleh Connolly dan Begg (2005), terdapat 9 tahap metodologi dalam membangun data warehouse yang dikenal dengan nine-step methodology yakni: (1) Memilih proses. (2) Memilih grain. (3) Identifikasi dan menyesuaikan dimensi. (4) Memilih fakta. (5) Menyimpan pre-kalkulasi dalam tabel fakta. (6) Melengkapi tabel dimensi. (7) Memilih durasi dari database. (8) Melacak perubahan dimensi secara perlahan. (9) Menentukan prioritas dan mode query.

\section{METODE}

Metode pengumpulan data dilakukan melalui tahap: (1) Studi Kepustakaan yaitu melakukan tinjauan pada buku-buku yang berkaitan dengan topik skripsi untuk mendapatkan landasan teori yang berhubungan. Dilakukan pencarian, pengumpulan dan pembelajaran informasi dari berbagai buku literatur, jurnal, internet ataupun media informasi lainnya yang berhubungan dengan obyek penelitian sehingga dapat dijadikan sebagai landasan teori. (2) Interview yaitu melibatkan unit instansi lingkup badan ketahanan pangan baik pasar dan dagang, meliputi para kepala bidang, dan user yang menggunakan sistem sehingga dapat menganalisis dan mengidentifikasi manfaat dari prototype data warehouse yang telah dirancang. (3) Analisis kebutuhan sistem yaitu tahap ini dilakukan untuk mengetahui kebutuhan data warehouse, berdasarkan dari kegunaannya dan kebutuhan informasi dari instansi terkait. (4) Dokumen yaitu selain melalui wawancara dan observasi, informasi juga bisa diperoleh lewat fakta yang tersimpan dalam bentuk surat, catatan harian, buku panduan, arsip foto, hasil rapat, cenderamata, jurnal kegiatan, struktur organisasi dan sebagainya. Data berupa dokumen seperti ini bisa dipakai untuk menggali infomasi yang terjadi di masa lampau.

Metode perancangan data warehouse dengan menggunakan nine step methodology yang dikutip dari buku (Kimball \& Ross, 2002), ada sembilan langkah yang harus dipenuhi agar dapat 
membuat sebuah sistem data warehouse yang baik yaitu: (1) Pemilihan proses (choosing the process). (2) Pemilihan grain (choosing the grain). (3) Identifikasi dan penyesuaian dimensi (identifying and conforming the dimensions). (4) Pemilihan fakta (choosing the facts). (5) Menyimpan perhitungan awal di tabel fakta (storing pre-calculation in the fact table). (6) Melengkapi table dimensi (rounding out the dimension tables). (7) Pemilihan durasi data warehouse (choosing the duration of the database). (8) Pelacakan perubahan dimensi secara perlahan (tracking slowly changing dimension). (9) Penentuan prioritas query dan mode query (deciding the query priorities and the query modes).

\section{HASIL DAN PEMBAHASAN}

Menurut Inmon (2002), Data warehouse adalah sekumpulan data yang sudah terintegrasi, berorientasikan subjek database yang dirancang untuk mendukung fungsi dari Decision Support System dimana data setiap unit tersebut relevan dengan waktu. Data warehouse berisi Data atomic dan lightly summarized Data. Data warehouse memiliki 4 karakteristik utama yaitu: (1) Subject Oriented yaitu sistem informasi klasik berorientasi pada aplikasi fungsional perusahaan. Untuk perusahaan asuransi contohnya, aplikasinya dapat berupa healthy, life, auto, casualty. Subjek dari sistem informasinya claim, customer, policy dan premium. (2) Integrated yaitu data diambil dari banyak sumber berbeda kemudian dimasukkan ke dalam data warehouse. Selama data diambil, diubah, dilakukan format kembali, diurutkan, diringkas dan seterusnya. Hasilnya adalah data yang terletak dalam Data Warehouse yang memiliki pandangan terpadu dan terintegrasi. (3) Non-Violatile adalah Data dalam lingkungan operasional di ubah secara teratur, tetapi Data pada Data Warehouse menunjukkan karakteristik yang berbeda. Data pada data warehouse di load dan diakses tetapi tidak di update. Ketika Data di load pada data warehouse dalam sebuah snapshot (static format). Ketika terjadi perubahan selanjutnya, snapshot yang baru akan ditulis. (4) Time variant adalah data yang tersimpan dalam data warehouse bersifat time-variant atau bersifat akurat pada periode tertentu. Karakteristik dasar data dalam data warehouse sangat berbeda dengan data dalam OLTP, dimana data hanya akurat sesaat setelah data diakses, sedangkan data pada data warehouse, data akurat selama periode waktu tertentu, maka dikatakan memiliki rentang waktu (time variant).

Dari definisi diatas dapat disimpulkan bahwa data warehouse berfungsi sebagai gudang data yang menyimpan data historical yang sudah terintegrasi, clean, konsisten sehingga dapat memberikan laporan dalam bentuk summary data dimana data tersebut dapat dilihat dari berbagai sudut pandang dan dapat dilakukan drill down. Selain itu report yang dihasilkan dari datawarehouse tidak akan memberikan partial analysis, sehingga keputusan top management akan lebih tepat dan akurat.

\section{Perancangan Data Warehouse}

Perancangan data warehouse pada Kementerian Pertanian dibutuhkan beberapa tahap hingga terbentuknya data warehouse. Metode yang digunakan adalah metode Nine-step Methodology dari Kimball. Tahap - tahap tersebut antara lain: (1) Pemilihan proses (Choosing the process) adalah proses yang terjadi pada Pusat Distribusi dan Cadangan Pangan adalah proses pada bidang distribusi, bidang cadangan dan bidang harga pangan. Proses ketiga bidang antara lain: Bidang Distribusi Pangan, Bidang Cadangan Pangan, dan Bidang Harga Pangan. (2) Pemilihan grain (Choosing the grain): Laporan PembelianKomoditas Mentah, Laporan Pembelian Bahan Cadangan, Laporan Distribusi Masuk, Laporan Distribusi Keluar, Laporan Cadangan Keluar, Laporan Harga Konsumen, Laporan Harga Produsen. (3) Identifikasi dan penyesuaian dimensi (Identifying and conforming the dimensions): Pada tahap ini dilakukan penentuan dimensi yang berpengaruh terhadap grain diatas. Berikut adalah contoh dimensi-dimensi pada fakta pembelian komoditas mentah yang digunakan dalam data warehouse pada Kementerian Pertanian. 
Dimensi pada Fakta Pembelian Komoditas Mentah antara lain: (1) Dimensi Komoditas Mentah yang berisi detail mengenai jenis dan jumlah komoditas mentah yang dibeli. (2) Dimensi Pelaku Distribusi yang berisi detail lokasi dan banyaknya para pelaku distribusi di setiap daerah. (3) Dimensi Produsen yang berisi detail lokasi dan banyaknya produsen di setiap daerah. (4) Dimensi Transportasi yang berisi detail jenis dan jumlah transportasi yang dapat digunakan untuk melakukan distribusi. (5) Dimensi Waktu yang berisi detail mengenai waktu.

Tabel 1 Fakta Pembelian Komoditas Mentah

\begin{tabular}{|c|c|c|c|c|c|}
\hline Dimensi & $\begin{array}{c}\text { Dimensi } \\
\text { Komoditas } \\
\text { Mentah }\end{array}$ & $\begin{array}{c}\text { Dimensi } \\
\text { Pelaku } \\
\text { Distribusi }\end{array}$ & $\begin{array}{c}\text { Dimensi } \\
\text { Produsen }\end{array}$ & $\begin{array}{c}\text { Dimensi } \\
\text { Transportasi }\end{array}$ & $\begin{array}{c}\text { Dimensi } \\
\text { Waktu }\end{array}$ \\
\hline $\begin{array}{c}\text { Rata2VolumePembelian } \\
\text { KomoditasMentah }\end{array}$ & $\mathrm{x}$ & & & $\mathrm{x}$ & $\mathrm{x}$ \\
\hline $\begin{array}{c}\text { MaxVolumePembelian } \\
\text { KomoditasMentah }\end{array}$ & $\mathrm{x}$ & & & $\mathrm{x}$ & $\mathrm{x}$ \\
\hline $\begin{array}{c}\text { Rata2HargaPembelian } \\
\text { KomoditasMentah }\end{array}$ & $\mathrm{x}$ & $\mathrm{x}$ & $\mathrm{x}$ & $\mathrm{x}$ \\
\hline $\begin{array}{c}\text { MaxHargaPembelian } \\
\text { KomoditasMentah }\end{array}$ & $\mathrm{x}$ & $\mathrm{x}$ & $\mathrm{x}$ & & $\mathrm{x}$ \\
\hline
\end{tabular}

Pada tahap pemilihan fakta (choosing the facts), hal yang dilakukan berikutnya adalah menentukan fakta tabel. Berikut adalah contoh tabel fakta pembelian komoditas mentah.

Tabel 2 Fakta Pembelian Komoditas Mentah

\begin{tabular}{|c|c|c|c|}
\hline Proses Bisnis & Measure & Tabel Fakta & Isi \\
\hline $\begin{array}{c}\text { - Bidang Distribusi } \\
\text { Pangan } \\
\text { - Bidang Harga } \\
\text { Pangan }\end{array}$ & $\begin{array}{c}\text { - Rata2 Volume } \\
\text { Pembelian } \\
\text { Komoditas Mentah, } \\
\text { - Max Volume } \\
\text { Pembelian } \\
\text { Komoditas Mentah, } \\
\text { - Rata2 Harga } \\
\text { Pembelian } \\
\text { Komoditas Mentah } \\
\text { - Max Harga } \\
\text { Pembelian } \\
\text { Komoditas Mentah }\end{array}$ & $\begin{array}{c}\text { Fakta Pembelian } \\
\text { Komodias } \\
\text { Mentah }\end{array}$ & $\begin{array}{c}\text { - Kode Komoditas } \\
\text { Mentah } \\
\text { - Kode Produsen } \\
\text { - Kode Transportasi } \\
\text { - Kode Waktu } \\
\text { - Kode Pelaku } \\
\text { Distribusi } \\
\text { - Rata2 Volume } \\
\text { Pembelian } \\
\text { Komoditas Mentah, } \\
\text { - Max Volume } \\
\text { Pembelian } \\
\text { Komoditas Mentah, } \\
\text { - Rata2 Harga } \\
\text { Pembelian } \\
\text { Komoditas Mentah } \\
\text { - Max Harga } \\
\text { Pembelian } \\
\text { Komoditas Mentah }\end{array}$ \\
\hline
\end{tabular}


Dalam tahap menyimpan perhitungan awal di tabel fakta (storing precalculation in the fact table), kalkulasi awal pada tabel fakta terhadap data dapat dihitung. Kalkulasi awal yang terdapat pada tabel Fakta Pembelian Komoditas Mentah: (1) Rata2 Volume Pembelian Komoditas Mentah merupakan rata-rata dari total volume pembelian komoditas mentah dibagi dengan total dilakukannya transaksi. (2) Max Volume Pembelian Komoditas Mentah merupakan nilai maximum dari volume pembelian komoditas mentah di seluruh transaksi. (3) Rata2 Harga Pembelian Komoditas Mentah merupakan rata-rata dari total harga pembelian komoditas mentah dibagi dengan total dilakukannya transaksi. (4) Max Harga Pembelian Komoditas Mentah merupakan nilai maksimum dari harga pembelian komoditas mentah di seluruh transaksi.

Pada tahap melengkapi table dimensi (rounding out the dimension tables), tabel dimensi dikaji kembali dan melengkapi deskripsi sejelas mungkin kedalam dimensi dimana dapat dimengerti dan dipahami dengan baik oleh user. Berikut adalah contoh dimensi komoditas dan dimensi komoditas mentah yang dikaji kembali.

Tabel 3 Contoh Dimensi Komoditas dan Dimensi Komoditas Mentah

\begin{tabular}{|c|c|c|}
\hline Nama Dimensi & Deskripsi & Isi \\
\hline Dimensi Komoditas & $\begin{array}{l}\text { Berisi detail mengenai jenis } \\
\text { dan jumlah komoditas yang } \\
\text { dibeli. }\end{array}$ & $\begin{array}{l}\text { - Kode Komoditas } \\
\text { - Id Komoditas } \\
\text { - Nama Komoditas } \\
\text { - Version } \\
\text { - Date From } \\
\text { - Date To }\end{array}$ \\
\hline $\begin{array}{c}\text { Dimensi Bahan Komoditas } \\
\text { Mentah }\end{array}$ & $\begin{array}{l}\text { Berisi detail mengenai jenis } \\
\text { dan jumlah komoditas } \\
\text { mentah yang dibeli. }\end{array}$ & $\begin{array}{l}\text { - Kode Komoditas Mentah } \\
\text { - Id Komoditas Mentah } \\
\text { - Nama Bahan Komoditas } \\
\text { Mentah } \\
\text { - Version } \\
\text { - Date From } \\
\text { - Date To } \\
\text { - Tanggal }\end{array}$ \\
\hline
\end{tabular}

Tahap pemilihan durasi data warehouse (choosing the duration of the database) berkaitan dengan seberapa jauh dan seberapa banyak data yang akan diproses pertama kali. Akan tetapi dikarenakan perancangan Data Warehouse masih berupa prototype dan masih menggunakan data dummy maka database dibuat dengan estimasi kisaran tahun 2014 - 2019. Dalam pelacakan perubahan dimensi secara perlahan (tracking slowly changing dimension), Perancangan Data Warehouse pada Kementerian Pertanian khususnya di Pusat Distribusi dan Cadangan dirancang dengan menggunakan cara yang ke 2 yaitu perubahan data membentuk record baru dengan surrogate key yang berbeda. Tujuannya adalah untuk menjaga agar data yang lama tidak dihapus dan tetap ada sehingga dapat diketahui perubahan yang terjadi antara data yang lama dengan data yang baru. Pada tahap terakhir, penentuan prioritas query dan mode query (deciding the query priorities and the query modes), merupakan langkah dimana menentukan prioritas dalam penentuan laporan yang ingin ditampilkan untuk meningkatkan kinerja dari hasil laporan yang dihasilkan. 


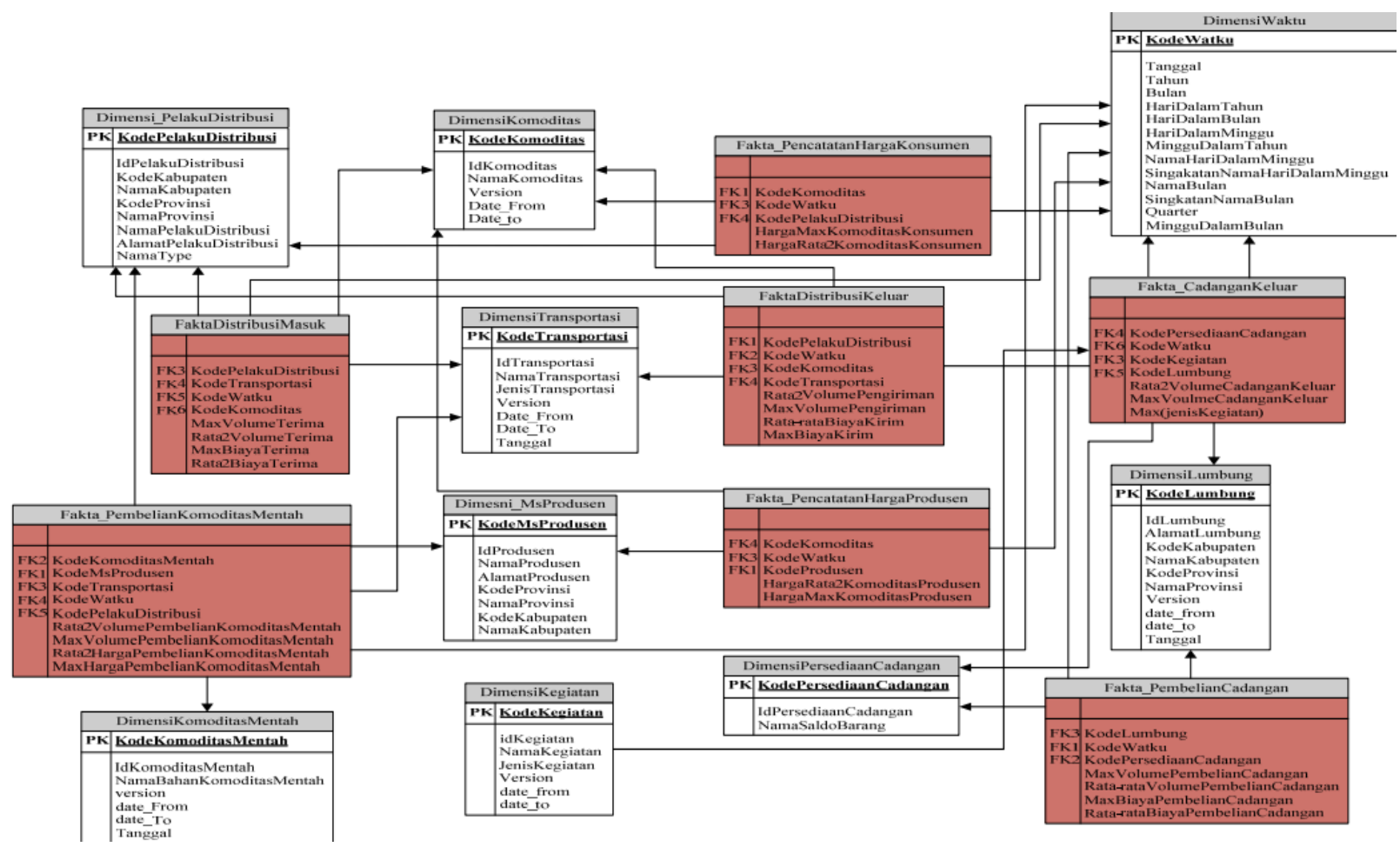

Gambar 2 Star Schema Keseluruhan

Pentaho adalah kumpulan aplikasi Business Intelligence (BI) dan data warehouse free open source software yang berjalan di atas platform Java. Aplikasi-aplikasi Pentaho dikembangkan oleh Pentaho corp yang berpusat di Orlanda, Amerika Serikat. Adopsi Pentaho cukup luas di Indonesia. Selain sifatnya gratis dan adopsi yang semakin hari semakin luas, dukungan Pentaho bisa didapatkan dari Pentaho Corp yang berpusat di Orlanda, Amerika Serikat. Dukungan ini dalam bentuk dukungan Service Level Agreement (SLA) dan dinamakan dengan versi Enterprise Edition. SLA ini sifatnya annual subscription. Selain itu jika Anda tetap menggunakan community edition yang free maka bisa mendapatkan dukungan dari banyak system integrator Pentaho di seluruh dunia termasuk di Indonesia.

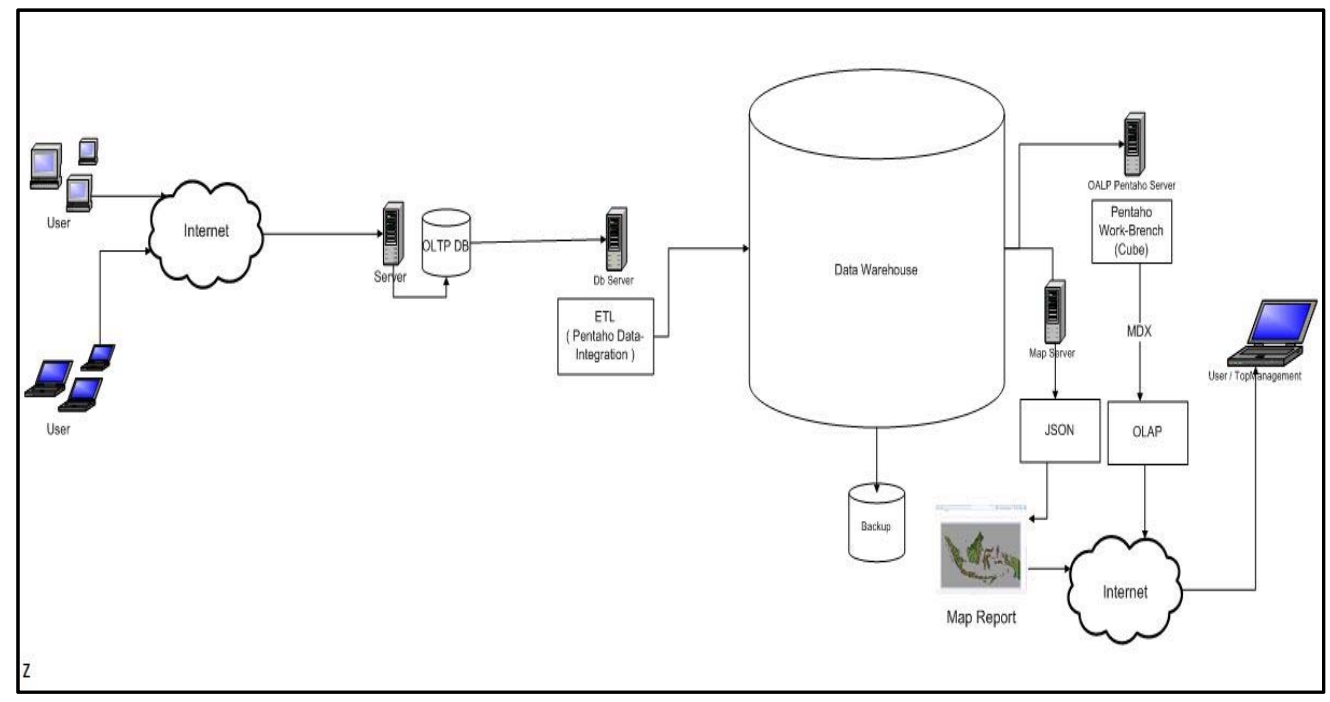

Gambar 3 Arsitektur Datawarehouse pada Kementerian Pertanian 


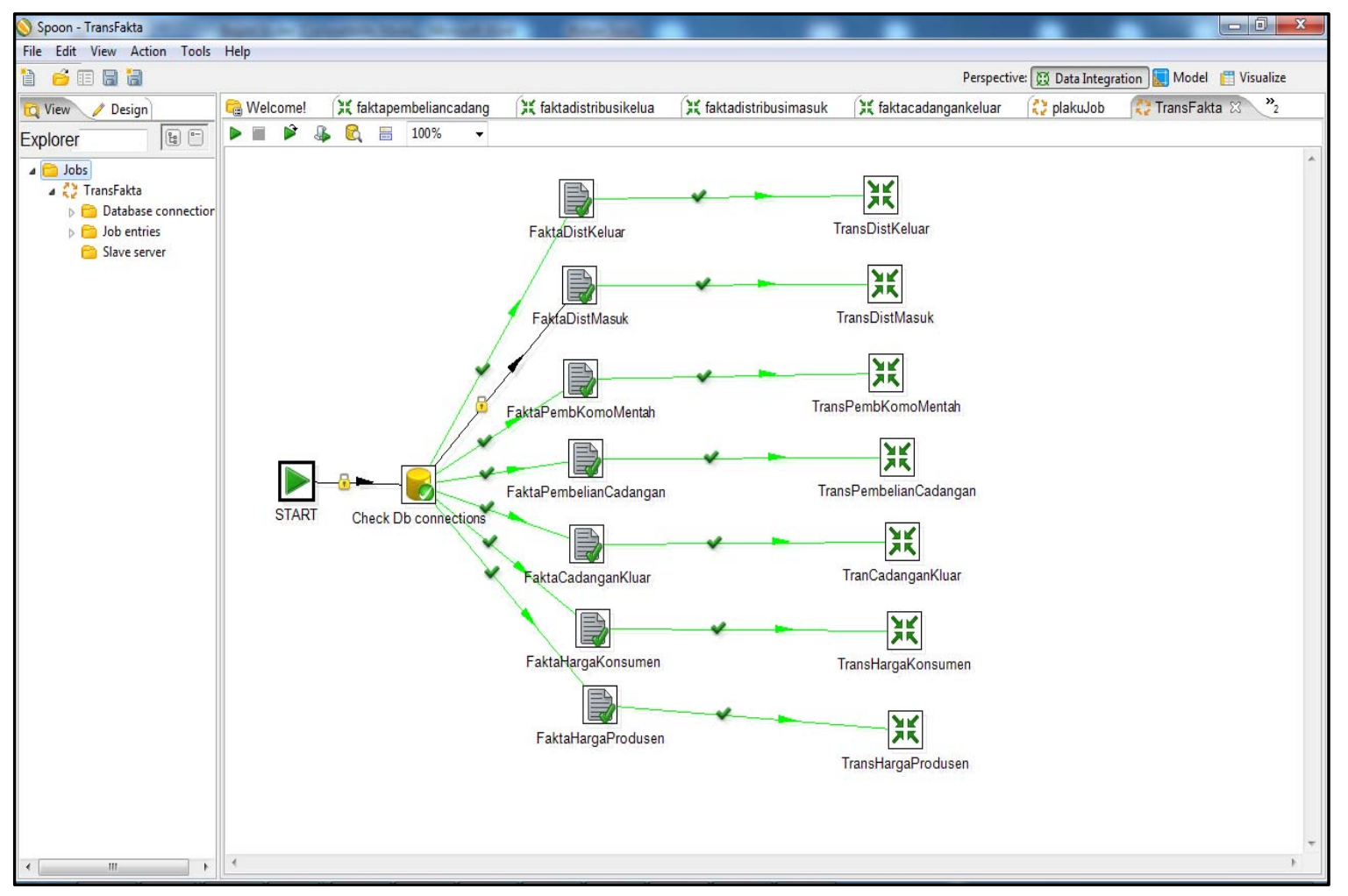

Gambar 4 Contoh Job Data Integration yang dibuat pada Kementerian pertanian

Berikut adalah kumpulan aplikasi Pentaho: Pentaho Reporting, Pentaho Analysis - Mondrian OLAP Engine, Pentaho Data Mining - Weka, Pentaho BI Server Platfom.

\section{Pentaho Data Integration}

Kettle atau dikenal juga dengan nama Pentaho Data Integration adalah software ETL (Extract, Transform and Load) open source yang: Designer GUI (Graphical User Interface), lebih dari 140 modul pengolahan data, berjalan di atas multi platform, lisensi Open Sourc, dukungan terhadap file dan berbagai database yang populer seperti Excel 2003, Excel 2007, SQL Server, MySQL, Oracle, dll. Keuntungan menggunakan Kettle adalah User akan mudah mempelajari dan menggunakannya dalam mengolah data sehari-hari dengan aplikasi designer dan modul Kettle yang straightforward. Dengan modul yang sangat kaya, user akan lebih mudah dalam mempersiapkan data yang variatif dan kompleks. Bersifat multi platform sehingga jika cost menjadi pertimbangan maka Kettle yang berjalan di atas sistem operasi gratis seperti Linux dapat menjadi solusi yang baik. Selain itu kettle dapat diotomatisasi dengan script yang sederhana.

\section{Pentaho Analysis / Mondrian OLAP Server}

Mondrian adalah open source OLAP (Online Analytical Processing) Server, yang berjalan di platfom java. Mondrian mendukung MDX (multidimensional expressions), XML and olap4j yang digunakan untuk menampilkan report dalam bentuk chart dan pivot table. 


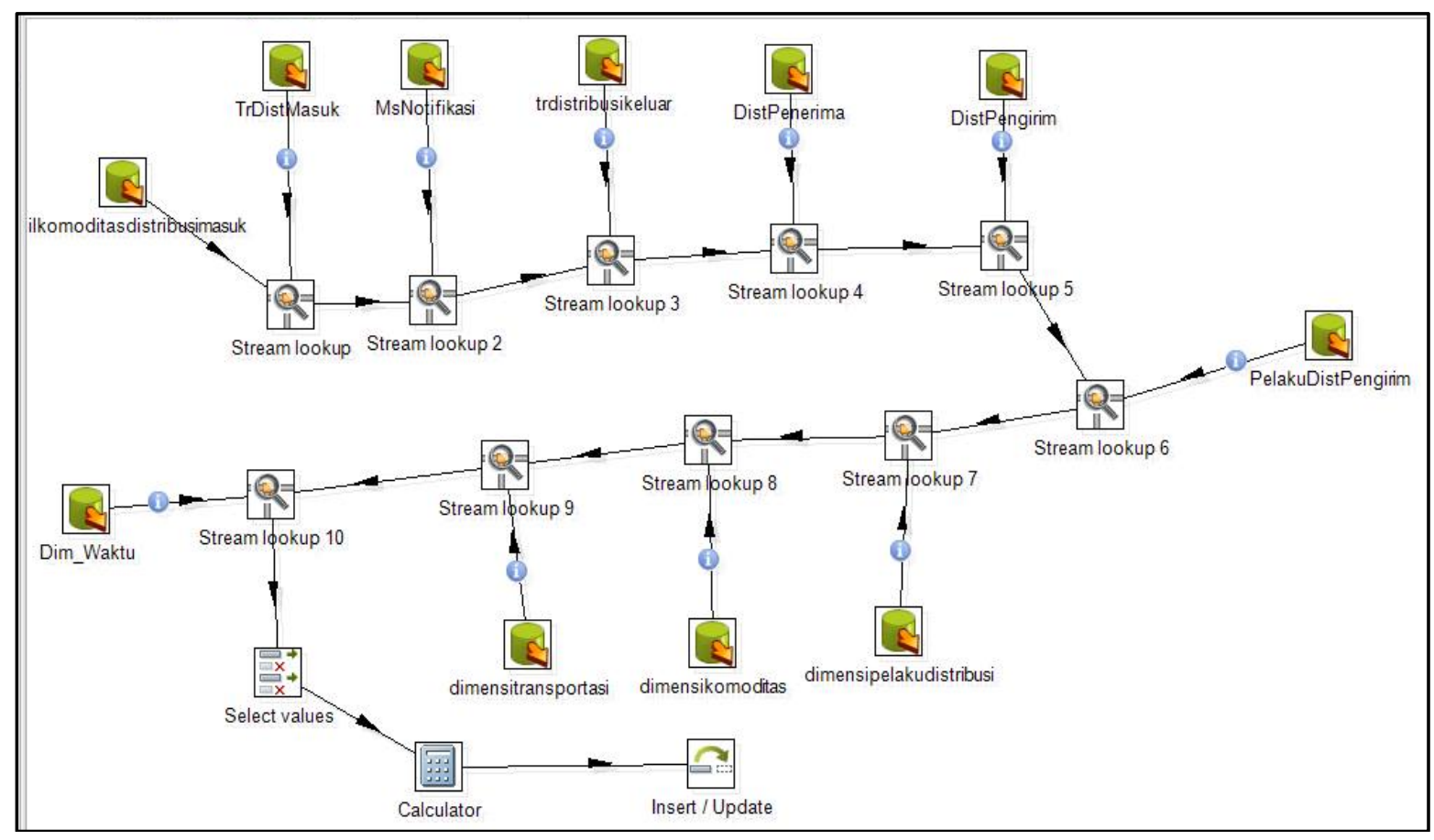

Gambar 5 Contoh Transformation Data Integration yang dibuat pada Kementerian pertanian

Keunggulan Mondiran OLAP Server: OLAP Server adalah open source terpopuler dan digunakan di berbagai produk BI open source (Pentaho dan Jasper), Multi Platform. Mondrian merupakan tipe ROLAP (Relational OLAP) dimana semua perintah data query diterjemahkan via SQL dan ditujukan kepada datamart, mendukung datamart dengan rancangan multi dimensional Star Schema maupun Snowflake Schema, mendukung query MDX (Multidimensional Expression) sebagai standar industry, didukung oleh beberapa aplikasi interface baik web based maupun desktop seperti JPivot, Pentaho Reporting, Pentaho Analysis Tools, dan Pentaho Analyzer. Semua interface di atas memiliki kemampuan drill down / roll up serta drill through untuk melihat detil penyusun sel-sel nilai analisis.

\section{Report}

Report atau laporan yang dihasilkan dari perancangan Data Warehouse ini berupa pivot table, chart dan map report, dimana top management dapat lebih mudah memahami informasi yang ada untuk dapat mengambil keputusan yang cepat dan tepat. Berikut adalah contoh hasil report pada Kementerian Pertanian. 


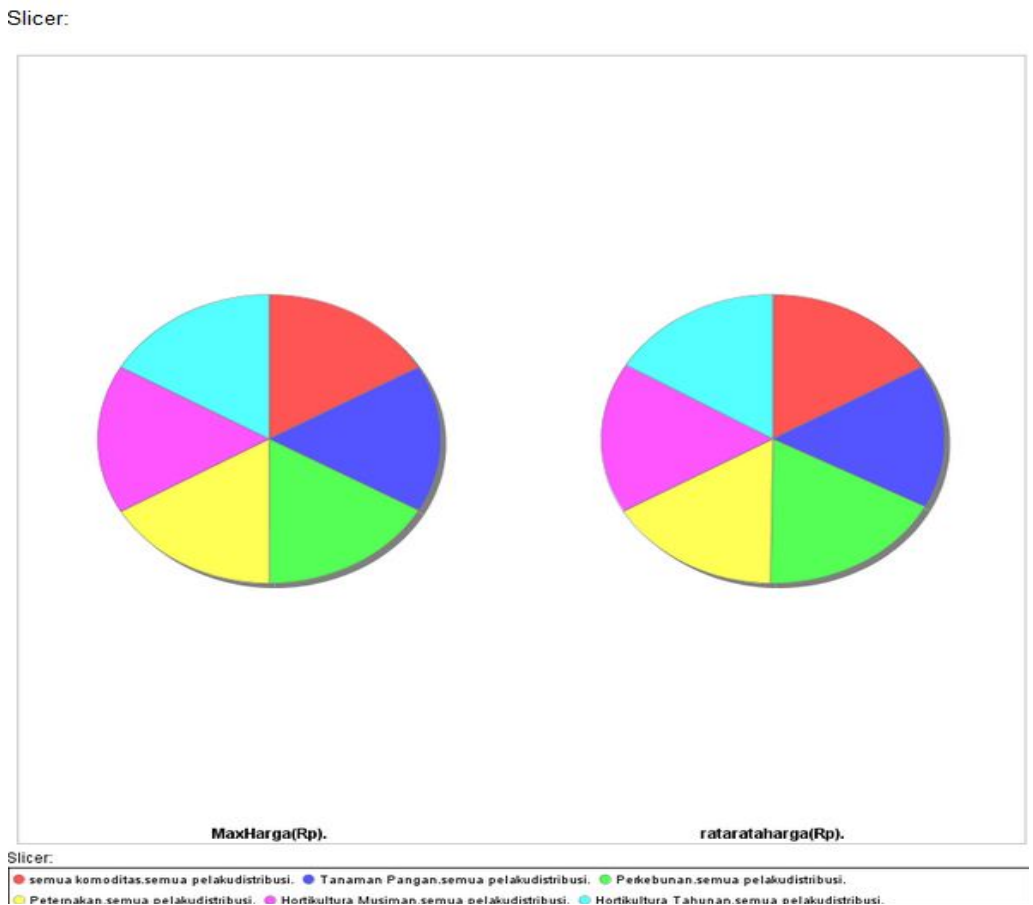

Gambar 6 Report Fakta Harga Konsumen

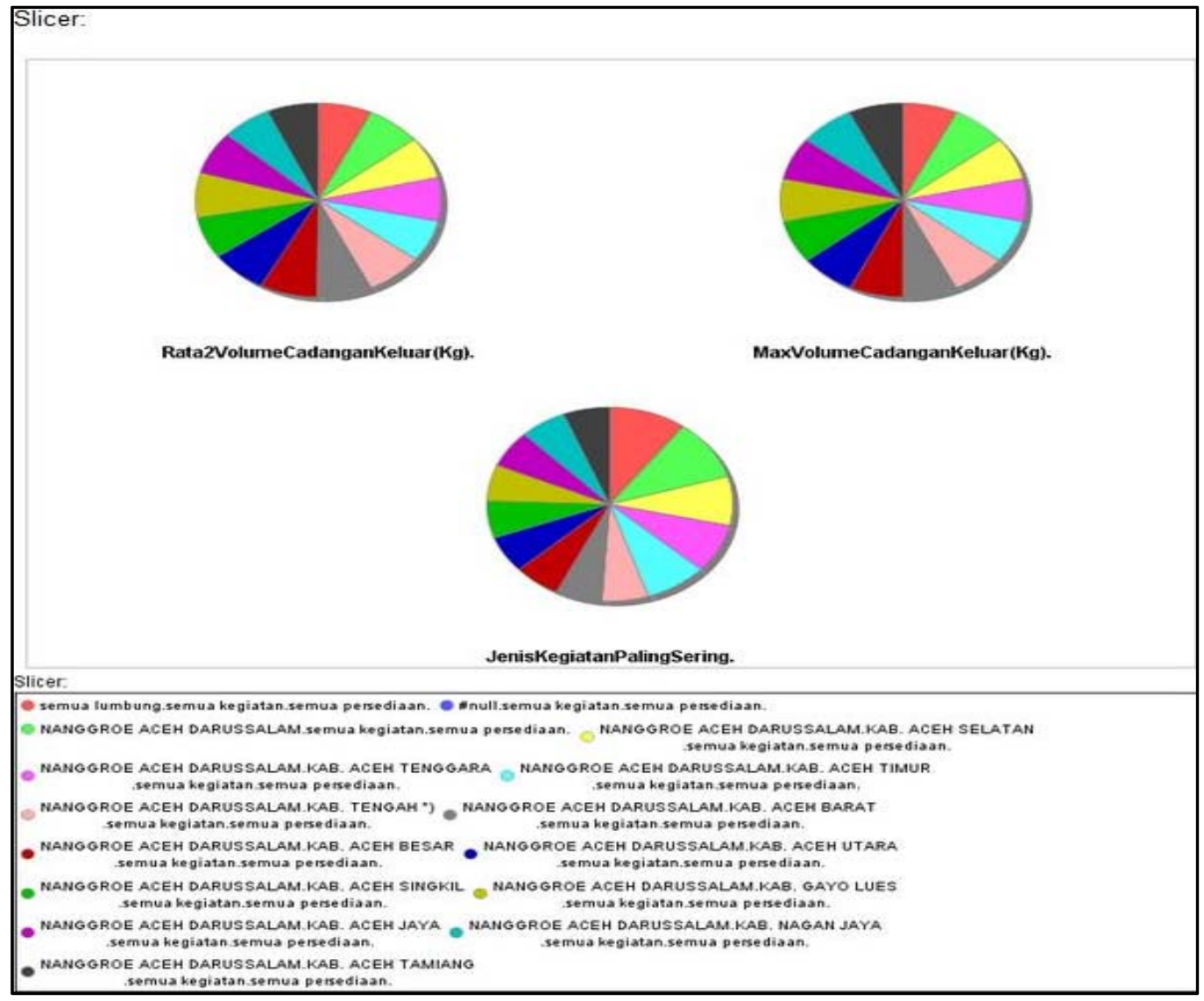

Gambar 7 Report Fakta Cadangan Keluar 


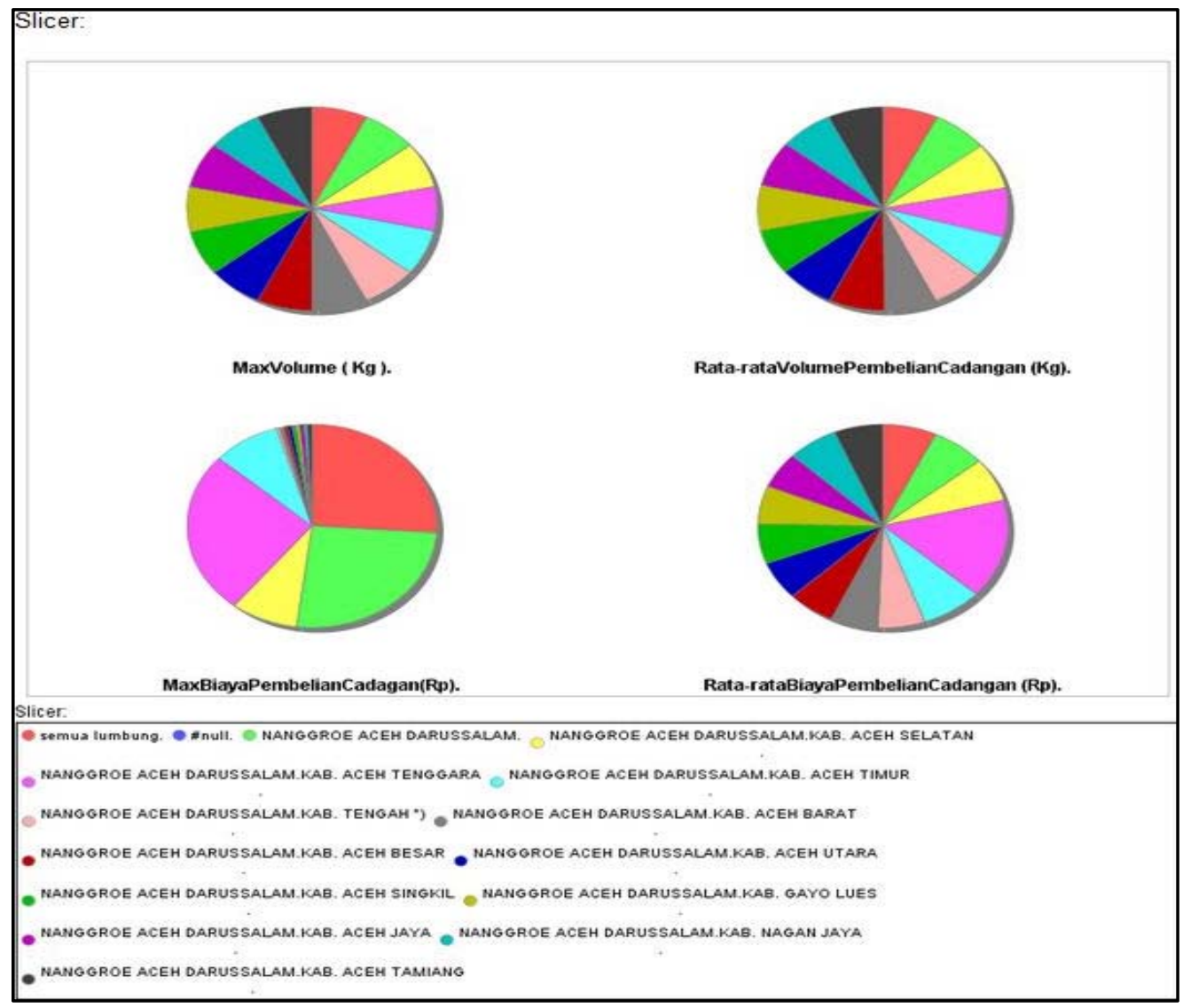

Gambar 8 Report Fakta Pembelian Cadangan

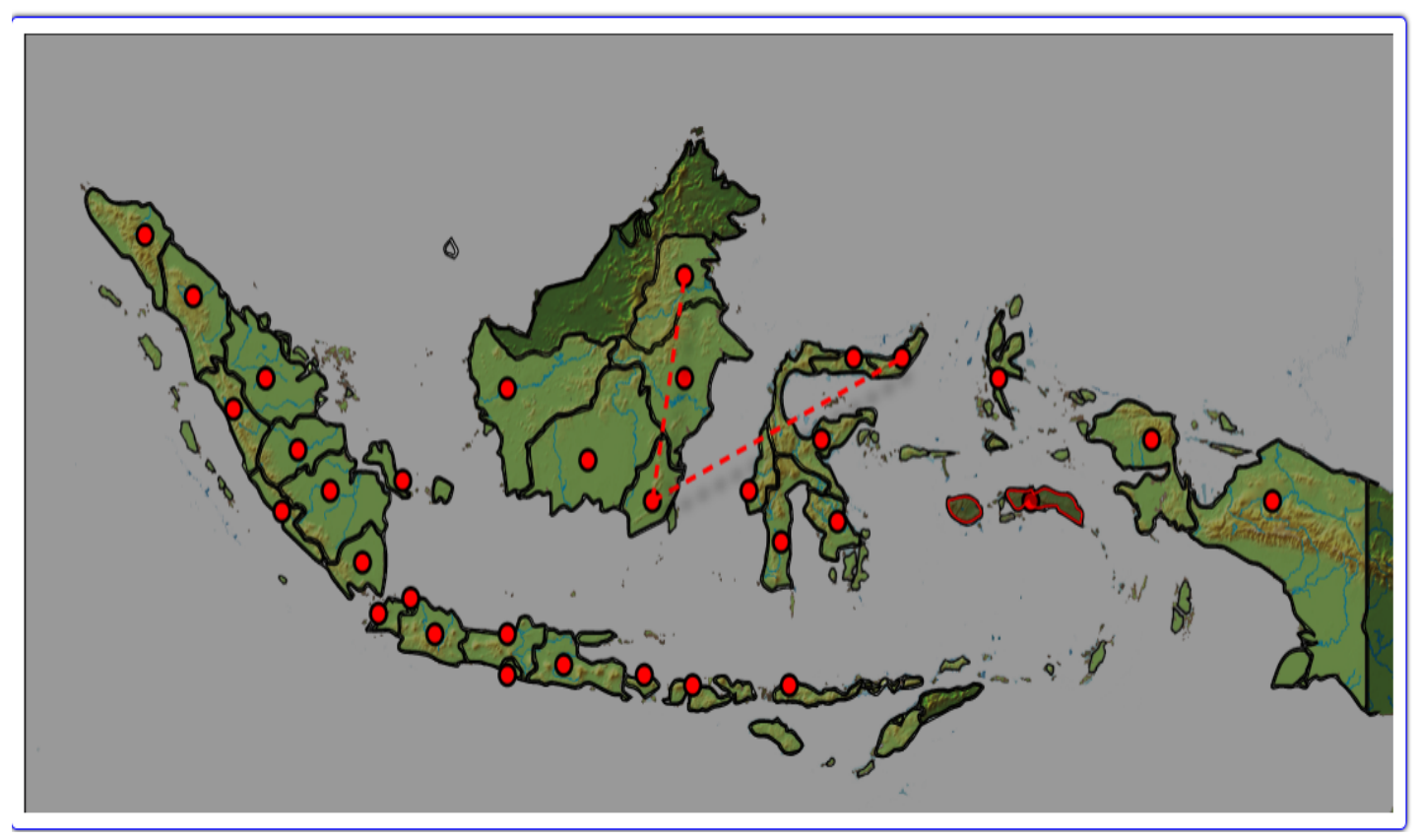

Gambar 9 Map Report 


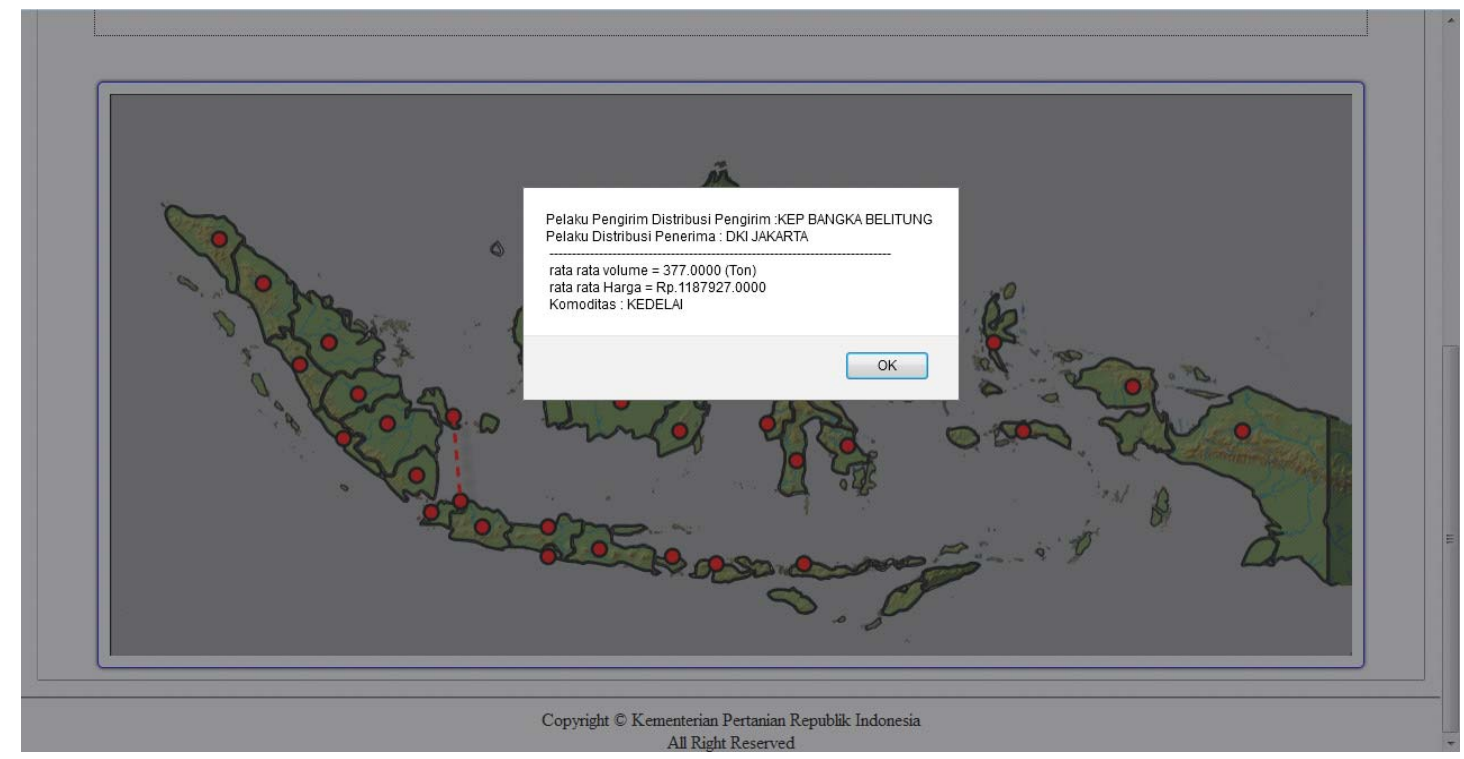

Gambar 10 Map Report Interaction

\section{SIMPULAN}

Dari hasil analisis ditemukan beberapa masalah atau hambatan di Kementerian Pertanian. Alasan tersebutlah yang melatarbelakangi dilakukannya Perancangan Database dan Prototype data warehouse. Kesimpulan yang diperoleh antara lain: (1) Data warehouse dapat memudahkan pemantauan harga di konsumen dan produsen yang dapat dilihat pada bebagai sudut pandang, misalnya sudut pandang waktu, komoditas, daerah dan lain-lain. serta dapat melakukan analisis fluktuasi harga pangan yang terus berubah menggunakan data historical. (2) Data warehouse mempermudah proses tracking arus distribusi antar daerah sehingga alur distribusi yang sebelumnya belum jelas karena terlalu detail menjadi jelas dan mudah di pantau. Tracking alur distribusi dapat dilihat menggunakan map, pivot table dan chart yang menyajikan data dalam bentuk summary data dimana dapat dilakukan Drill down yang memudahkan Top Management dalam mengambil keputusan. (3) Data warehouse dapat menghasilkan laporan terkait distribusi, cadangan dan harga pangan ke dalam bentuk yang summary. Dengan menggunakan data warehouse proses transaksi pada OLTP tidak akan terganggu karena report hanya akan dibuat dari data warehouse, selain itu report yang di hasilkan data warehouse tidak akan menampilkan informasi yang partial karena sifat dari data warehouse adalah historical bukan transactional.

Adapun saran yang dapat diperhatikan dan dipertimbangkan oleh Kementerian Pertanian khususnya Pusat Distribusi dan Cadangan Pangan di ketiga bidang yaitu bidang Distribusi, Cadangan dan Harga yang mungkin dapat bermanfaat di waktu kedepannya. Saran tersebut antara lain: (1) Melakukan pengembangan data warehouse lebih lanjut sesuai dengan perubahan-perubahan yang terjadi di waktu yang akan datang. (2) Memperluas ruang lingkup penggunaan data warehouse sehingga penggunaan data warehouse tidak hanya pada Pusat Distribusi dan Cadangan Pangan tetapi juga di seluruh pusat termasuk bidang lainnya yang ada di dalam Kementerian Pertanian yang berguna menghasilkan informasi yang akurat agar tepat dalam mengambil sebuah keputusan. (3) Melakukan pengawasan di tahap awal implementasi pada proses ETL agar kualitas data yang dihasilkan benarbenar konsisten dan bersih sehingga informasi yang di hasilkan tidak partial atau salah. 


\section{DAFTAR PUSTAKA}

Connoly, T.M., Begg, C.E. (2005). Database Systems: a practical approach to design, implementation, and management, Fourth Edition. Harlow, England: Addison-Wesley.

Inmon, W.H. (2002). Building the Data Warehouse, Third Edition. John Wiley \& Sons, Inc, New York.

Kimball, R., Ross, M. (2002). The Data Warehouse Toolkit: the complete guide to dimensional modelling, Second Edition. New York: John Wiley \& Sons, Inc.

McLeod, R., Schell, G. (2007). Management Information System. Tenth Edition. New Jersey: Pearson Prentice Hall.

Ponniah, P. (2001). Data Warehousing Fundamentals. USA: John Wiley \& Sons, Inc.

Turban, E., Rainer, R. K., \& Potter, R. E. (2005). Introduction to Information Technology. ${ }^{\text {rd }}$ Edition. Canada: John Wiley \& Sons. 